\title{
A new interstitial species of Gammarella (Amphipoda, Gammaridea) from the western Mediterranean Sea
}

\author{
Amparo Martí \& Santiago Villora-Moreno* \\ Marine Biology Laboratory, Department of Animal Biology, Faculty of Biology, E-46100 Burjassot, \\ Valencia, Spain; * present address: Observatoire Océanologique de Banyuls, Université Pierre \& Marie \\ Curie - CNRS, F-66650 Banyuls-sur-mer, France
}

Keywords: Chafarinas Archipelago, western Mediterranean, marine Amphipoda, taxonomy, Gammarella, new species

\begin{abstract}
A new species of Gammarella Bate, 1857 is described from shallow water, inhabiting the interstitial system in soft bottoms of the Chafarinas Archipelago (western Mediterranean, N. Africa). The relationships of Gammarella with the genera Nuuanu and Cottesloe are briefly discussed. Numerical taxonomic methods are utilized to differentiate between the morphologically related species and the intermediate species. In a table the principal differentiating characters of Gammarella species are presented. Gammarella garciai $\mathbf{n}$. sp. is characterized by its intermediate position between Gammarella, Nuuanu and Cottesloe, showing an intergradation of characters. Gammarella garciai n. sp. and G. merringannee show ecologically intermediate characters between the larger species, probably nestling, with preference for lightless environments, and the smaller species. The group of smaller species, with eyes poorly developed or absent, show interstitial preferences. A map of the world distribution and a key to the 11 known Gammarella species are presented.
\end{abstract}

\section{Resumen}

Se describe una nueva especie de Gammarella Bate, 1857 procedente del ambiente intersticial de los fondos de sustratos sueltos poco profundos del Archipiélago de Chafarinas (Mediterráneo occidental, N. Africa). Se discuten brevemente las relaciones de Gammarella con los géneros Nuuanu y Cottesloe. A partir de métodos de taxonomia numérica se distinguen las especies morfológicamente afines de las especies intermedias. En una tabla se presentan los principales caracteres disitintivos de las especies del género Gammarella. Gammarella garciai $\mathrm{n}$. sp. se caracteriza por su posición intermedia entre Gammarella, Nuuanu y Cottesloe, mostrando una intergradación de caracteres. Gammarella garciai n. sp. y G. merringannee presentan caracteres ecológicos intermedios entre las especies de mayor tamaño, probablemente anidadoras y con preferencia por ambientes poco iluminados, $y$ las especies pequeñas. Estas últimas tienen los ojos poco desarrollados o ausentes y muestran hábitos intersticiales. Se presen- tan una clave y un mapa con la distribucion mundial de las 11 especies conocidas de Gammarella.

\section{Introduction}

The taxonomic position of the genus Gammarella Bate, 1857 within the gammaridean Amphipoda is difficult to establish. The family Gammaridae (sensu lato) was split into a number of superfamilies (Bousfield, 1973, 1977; Barnard, 1976) and the only species known for the genus, Gammarella fucicola (Leach, 1814), was included in the family Melitidae. When Karaman \& Barnard (1979) started their revision, Gammarella was placed in "other Gammaridae'. Later, Barnard \& Barnard (1983: 141) established the term "Nuuanuids" to group the related genera Gammarella and Tabatzius McKinney \& Barnard, 1977. In the same work (Barnard \& Barnard, op.cit.: 636) both genera were also called "Gammarellids". Finally, Barnard \& Karaman (1987) considered the "Nuuanuids" as a family group, but they delayed the family name because "there is already a family Gammarellidae Bousfield (1977), based on the unrelated genus Gammarellus"' (op.cit.: 867).

The only species originally assigned to the genus was Gammarella hybophora Lowry \& Fenwick, 1983. The rest of the species, including the typespecies $G$. fucicola, have been described under actually synonymous genera, such as Pherusana J.L. Barnard, 1964; Nuuanu J.L. Barnard, 1970; Cottesloe J.L. Barnard, 1974; and Valettiella Griffiths, 


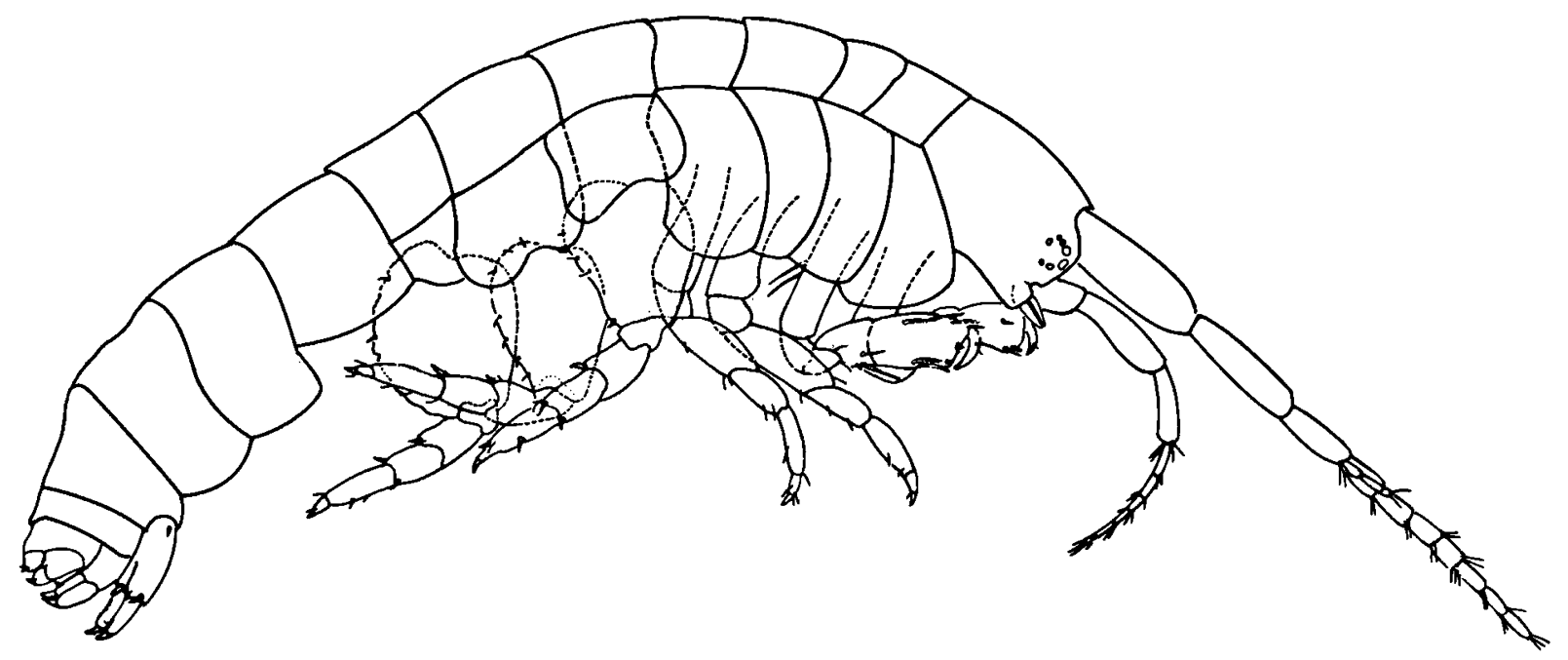

Fig. I. Gammarella garciai n. sp. १: lateral view of body.

1977 (see Karaman \& Barnard, 1979; Barnard \& Barnard, 1983; Barnard \& Karaman, 1987).

Karaman \& Barnard (1979) found a progression of morphological characters too broad to permit generic division. They concluded that "no discontiguity exists among Gammarella, Nuuanu, and Cottesloe (op.cit.: 157). Recently, Vonk (1988) considered the differences too large between Nuuanu and Gammarella "to make the use of such a genus workable". Consequently, he retained the genus Nuuanu, describing a new species Nuuanu curvata.

The present paper deals with a new species of the "nuuanuids", Gammarella garciai n. sp., collected from shallow-water soft bottoms from the Chafarinas Archipelago (western Mediterranean, N. Africa). This species shows intermediate characters between Gammarella, Cottesloe, and Nuuanu, making doubtful the validity of any generic division, thus forcing us to propose Gammarella curvata (Vonk, 1988) as a new combination for Vonk's species. Therefore, at present 11 species of Gammarella are recognized (cf. Barnard \& Barnard, 1990): G. fucicola (Leach, 1814), G. amikai (J.L. Barnard, 1970), G. berringar (J.L. Barnard, 1974), G. merringannee (J.L. Barnard, 1974), G. mokari (J.L. Barnard, 1974), G. numbadi (J.L. Barnard, 1974), G. castellana (Griffiths, 1977), G. cyclodactyla (Hirayama, 1978), G. hybophora Lowry \& Fenwick, 1983, G. curvata (Vonk, 1988), and G. garciai n. sp.

\section{Materials and methods}

Gammarella garciai n. sp. was collected during the CHAFARINAS'91 field survey in the Chafarinas Archipelago (southwestern Mediterranean, North Africa). Meiobenthos samples were collected by means of scuba diving from a shallow sublittoral pool ( $3 \mathrm{~m}^{2}$ area, $-4.2 \mathrm{~m}$ depth) near a Posidonia meadow, located south of the island Isabel II. General environmental and biological (meiofauna) characteristics of the study area were described by Villora-Moreno (1993). The animals were extracted from the sediment samples using a decantation technique with 7.5\% magnesium chloride in water. Material was fixed in buffered $10 \%$ formaldehyde in filtered seawater. Specimens were dissected in lactic acid and dissected parts were placed in glycerine mount. All drawings were prepared using a camera lucida on a Wild microscope. The type material has been deposited in the Museo Civico di Storia Naturale di Verona, Italy (MVR).

\section{Taxonomic part}

Gammarella garciai $\mathrm{n}$. sp.

(Figs. 1-4)

Material examined. - Holotype: (MVR Cr363, slides 38433846), male $2.5 \mathrm{~mm}$. Allotype: (MVR Cr363, slides 3847-3849), female $2.5 \mathrm{~mm}$. Paratypes: 3 specimens (MVR Cr363); 2 specimens (Museo nacional de Ciencias Naturales de Madrid, Spain). Type locality: southwestern Mediterranean, Chafarinas Archipelago, Isabel II island; collected by scuba diving east of "Titan" wharf (sta. IS11-CL1, 7 August 1991); well-sorted very coarse sand (mean diameter 1.56-1.77 mm) near Posidonia beds, depth $4.3 \mathrm{~m}$; July 1991, coll. S. Villora-Moreno. Other material: 
34 specimens from the type locality and 6 specimens from amphioxus gravel (sta. F6, 10 August 1991 and 22 February 1994), (Amphipoda coll., Marine Biology Laboratory of the University of Valencia, Spain).

Description of holotype. - Body (Fig. 1) length up to $2.5 \mathrm{~mm}$. Lateral cephalic lobe quadratiform, anteroventral notch present. Eyes poorly developed, composed of about eight widely scattered ommatidia. Urosome segments 2 without pair of dorsolateral spines. Cuticle heavily villose.

Adult male: Antenna 1 (Fig. 2A) reaching $1 / 2$ to $2 / 3$ of body length, not geniculate; peduncle long, segment 1 stout, naked, segment 2 more slender and equal to length of 1 , peduncle segment 3 nearly half length of segment 2 . Flagellum as long as peduncle. Primary flagellum up to 11 -articulate, poorly setose. Accessory flagellum 3-articulate, third segment short.

Antenna 2 (Fig. 2A) shorter than antenna 1: peduncle segment 3 short, segment 4 slightly longer than 5; flagellum 6-7-articulate and shorter than peduncle, poorly setose. Antennal gland cone short. Labrum (Fig. 2B) broader than long, with distal margin entirely fringed with fine hairs. Inner lobes of labium (Fig. 2I) very weak. Maxilla 1 (Figs. $2 \mathrm{G}-\mathrm{H})$ : inner plate large with 6-7 marginal plumose setae, outer plate with 8-9 distal multidenticulate spines, palp asymmetric with 2 articles, bearing 4-5 (right-left) distal spines and 2 subdistal setae. Maxilla 2 (Fig. 2E): both plates moderately long, bearing numerous setae at distal margin, inner plate with oblique medial row of 5-6 setae.

Maxilliped (Fig. 2F): inner plate moderately long, with 3 stout distal spines; outer plate not reaching top of palp segment 2 , with a row of 7 large spines at disto-internal margin; palp strong, with 4 segments, dactylus with distinct inner medial row of setules; nail short.

Mandible (Figs. 2C-D): molar and incisor well developed, rakers row with 5-6 denticulate strong setae. Left lacinia mobilis with 4 teeth, right lacinia mobilis with 2 teeth (inner denticulate). Palp short with 3 articles, articles 1 and 3 subequal and shorter than 2, article 1-2 smooth, article 3 not falciform, without D-setae and only 2 unequal E-setae.

Coxal plates 1-4 (Figs. 3A-B, 4A-B) large, longer than broad, coxal plates 1-2 with posterodistal notch with a small tooth, coxal plate 1 weakly dilated distally, coxal plate 4 not lobed, coxal plate 5 (Fig. 1) shorter than 4, bilobed distally.

Gnathopod 1 (Fig. 3A): basis with 2 long plumose setae medially on posterior margin; carpus not elongate, with pectinate setae; propodus slightly shorter than carpus, palm transverse and slightly convex, defined by apically bifid stout spines; dactylus stout, with one dorsal seta and 4-5 ventral setae.

Gnathopod 2 (Figs. 3B-C) much larger than gnathopod 1. Merus without distal tooth. Carpus triangular; propodus large and elongate, ovoid, palm short, convex, inclined, crenulate, provided with a row of short bifid palmar spines, separated from posterior margin by a tooth and two bifid spines.

Pereiopods 3-4 (Figs. 4A-B) with poorly spinose propodus, dactylus shorter than half of propodus, nail short. Dactylus with 2 setae, 1 posterior seta and the other at base of nail. Pereiopods 5-7 (Figs. 4C-E) short, base large, weakly serrate, with moderate posterodistal lobe; base of P5-6 weakly excavate posteriorly, tapering distally; base of $P 7$ broadly expanded, shield-like. Dactylus short, stout, as on pereiopods 3-4.

Epimeral plates 2-3 unextended, with small posterodistal tooth, almost smooth. Uropods 1-2 (Figs. 4G-H) rami short and subequal, with stout distal spines. Uropod 1: peduncle with one lateroproximal (basofacial) spine, one dorsal spine, and two strong distal spines at base of each ramus; rami with one dorsal spine. Uropod 2 shorter than 1 , nearly reaching end of uropod 1; peduncle with one distal spine, dorsal margin of outer ramus naked and inner ramus with 1 spine. Uropod 3 (Fig. 4I) very short, not reaching end of uropods 1-2; peduncle with distal spine. Outer ramus nearly half length of peduncle, article 1 with two unequal spines, article 2 small; inner ramus 1-articulate, scale-like, as long as article 1 of outer ramus. Telson (Fig. 4F) broader than long, fully cleft, each lobe with 4 distal setae.

Allotype: Female $2.5 \mathrm{~mm}$. Similar to holotype except gnathopod 2 (Fig. 3D) slender and elongate, 


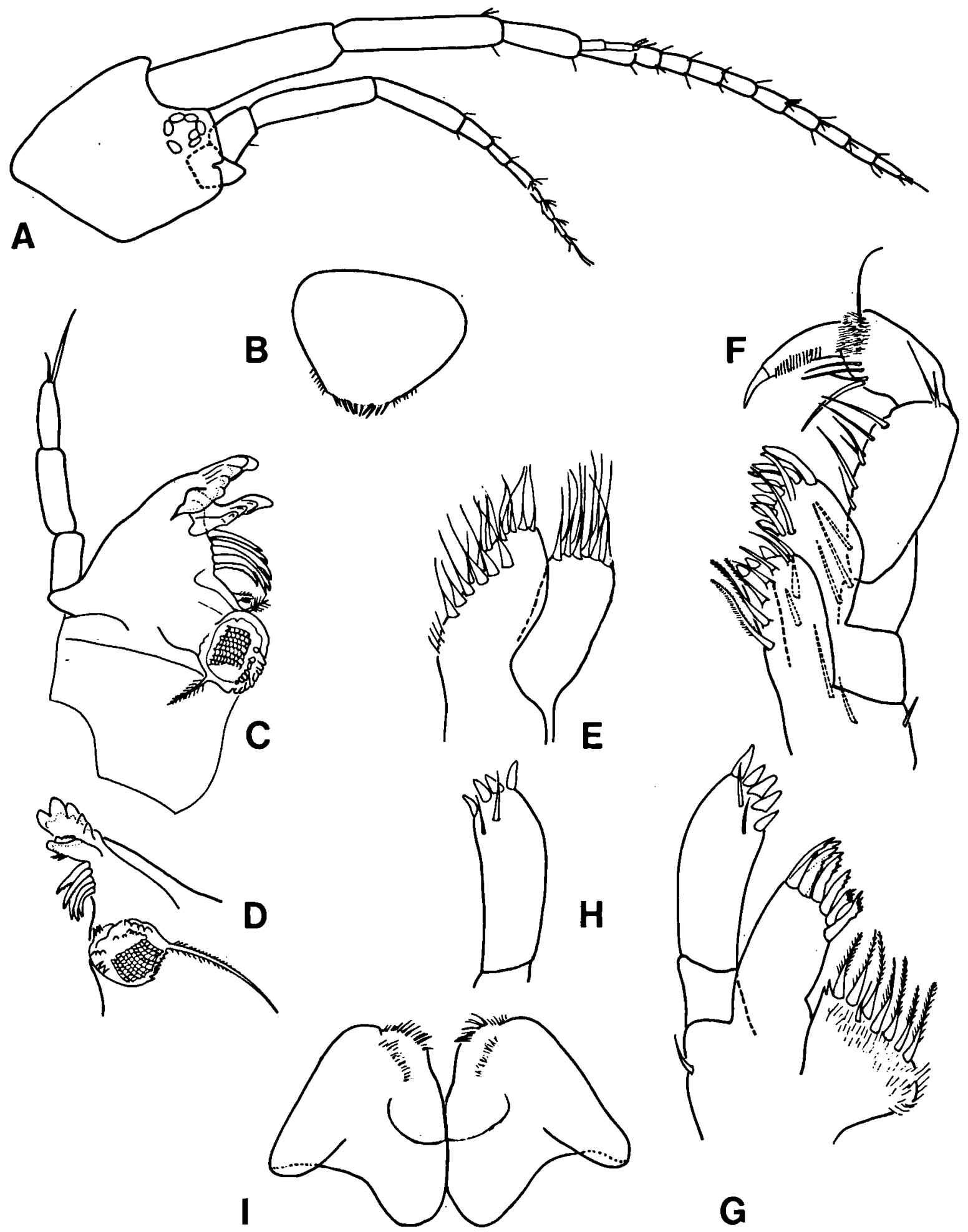

Fig. 2. Gammarella garciai $\mathrm{n}$. sp. ơ: A, head; B, labrum; C, left mandible; D, right mandible; E, maxilla 2; F, maxilliped; G, left maxilla $1 ; H$, palp of right maxilla $1 ; I$, labium. 

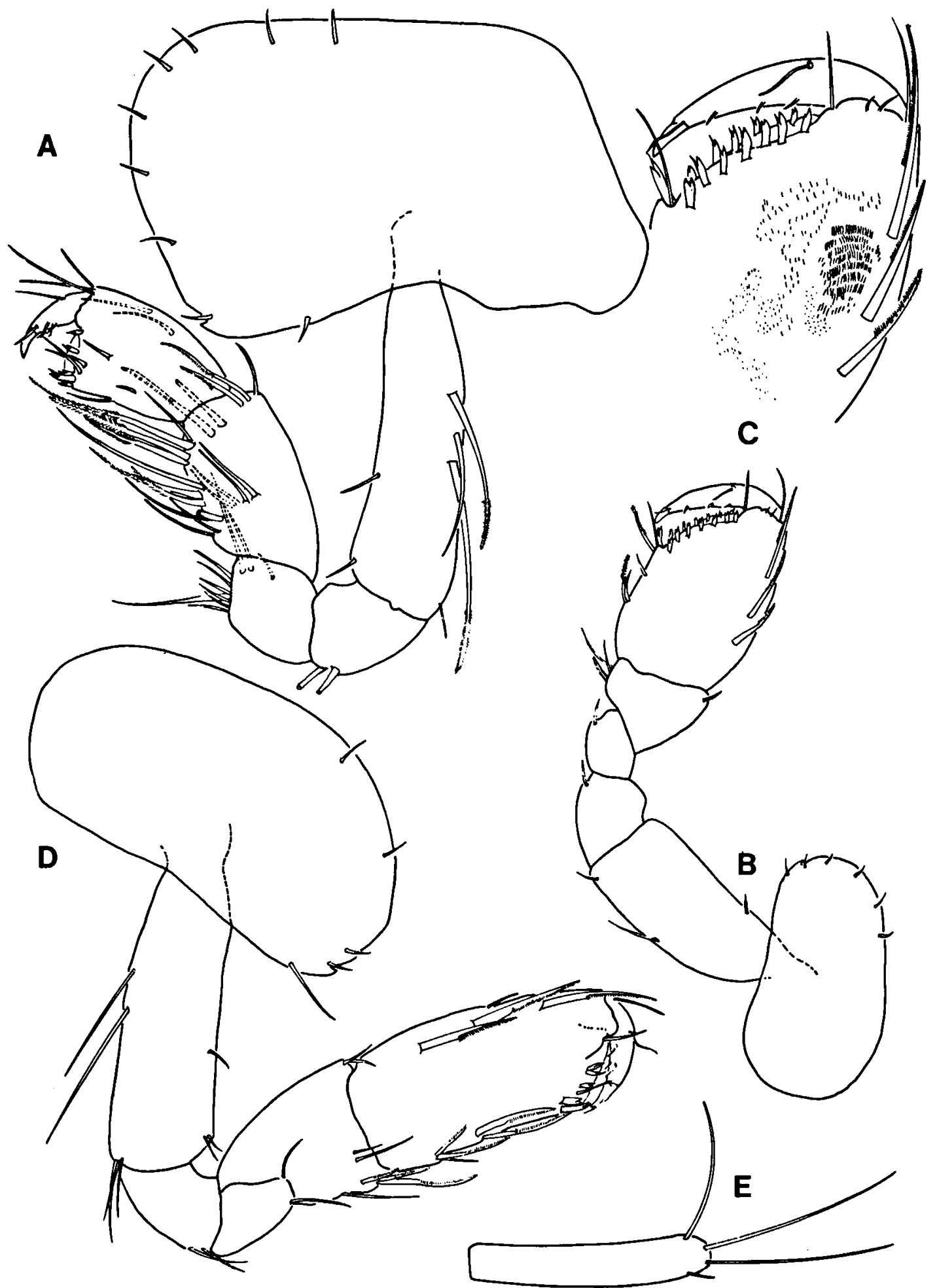

Fig. 3. Gammarella garciai n. sp.: A, gnathopod $1 \sigma ; \mathrm{B}$, gnathopod $2 \sigma\left(1 / 2\right.$ reduced); C, detail of palm of gnathopod $2 \sigma^{\circ}$; D, gnathopod 2 \&; E, oostegite of pereiopod 5 \& $(2 \times$ increased $)$. 


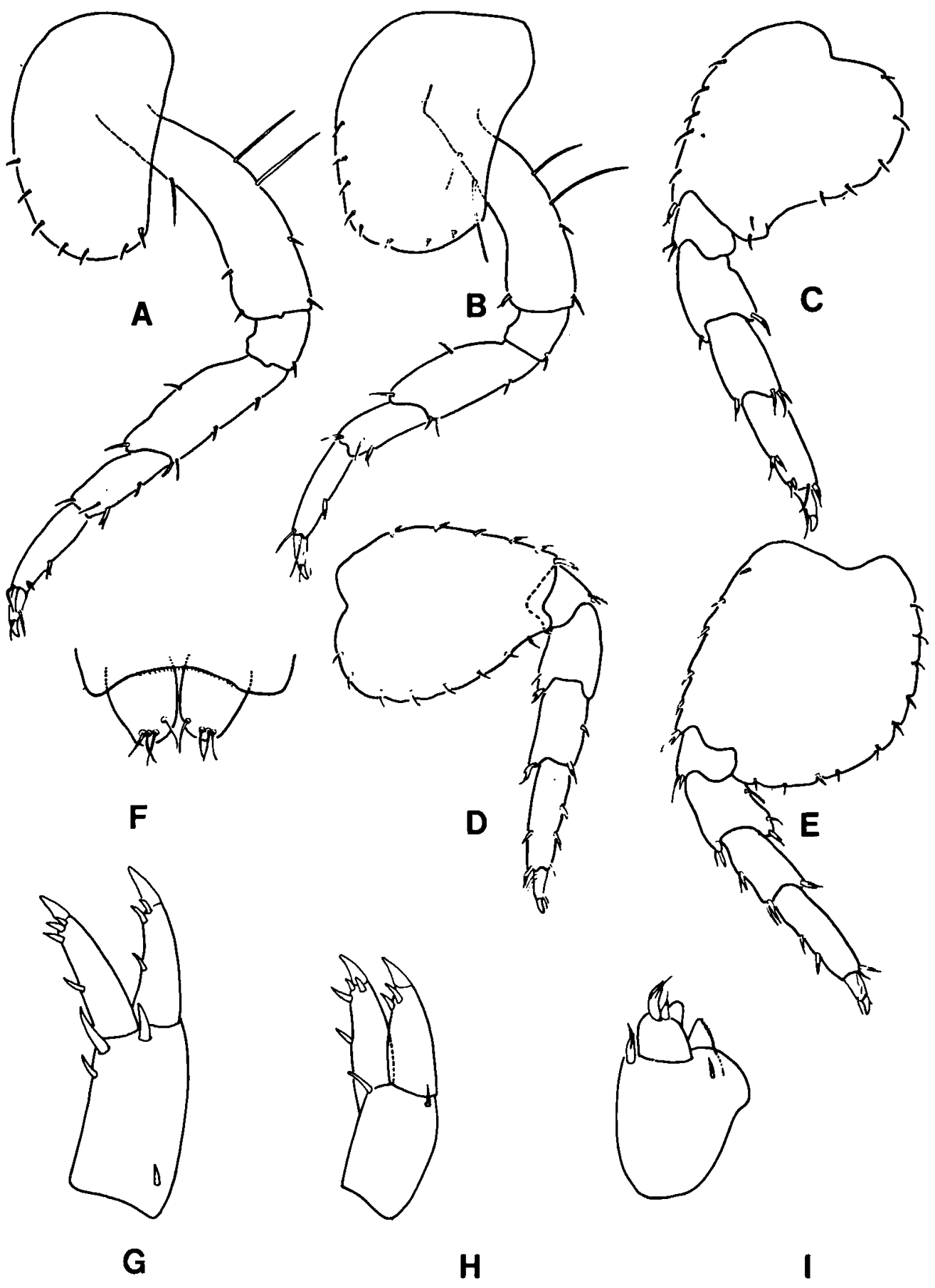

Fig. 4. Gammarella garciai n. sp. o: A, pereiopod 3; B, pereiopod 4; C, pereiopod 5; D, pereiopod 6; E, pereiopod 7; F, telson; G, uropod 1; H, uropod 2; I, uropod 3.

carpus subtriangular, larger than wide, propodus elongate with oblique palm defined by two large bifid spines.
Oostegites (Fig. 3E) on second to fifth pereiopods, narrow, armed with 3 long setae and 1 short seta. 
Table I. Matrix of values for 18 taxonomic characters used in the cluster analysis of Gammarella species $(1=$ presence, $0=$ absence): A, size < $6 \mathrm{~mm}$; B, sparse eyes; C, antenna 1 geniculate; D, accessory flagellum with 3 articles; E, mandible palp, article 2 without setae; F, mandible palp, article 3 with only E-setae; G, mandible palp not falciform; H, Gn1 carpus $<2 \times$ propodus; I, Gn2 ( $\sigma$ ), merus without distal tooth; J, Gn2 ( $\left.\sigma^{\circ}\right)$, carpus very short; K, Gn2 ( $\left.\sigma^{\circ}\right)$, palm short, defined from posterior margin; L, P3-4 propodus poorly spinose; $\mathrm{M}, \mathrm{P} 7$ base serrate (not castellated); N, epimeral plate 1 with an anteroventral curved tooth; 0 , metasomites 1-2 with a dorsal tooth each; $P$, uropod 3, inner ramus > 1/2 outer ramus; $Q$, telson without spines; $R$, telson fully cleft.

\begin{tabular}{|c|c|c|c|c|c|c|c|c|c|c|c|c|c|c|c|c|c|c|}
\hline & $\mathbf{A}$ & B & C & D & $\mathbf{E}$ & $\mathbf{F}$ & $\mathbf{G}$ & $\mathbf{H}$ & I & $\mathbf{J}$ & $\mathbf{K}$ & $\mathbf{L}$ & $\mathbf{M}$ & $\mathbf{N}$ & 0 & $\mathbf{P}$ & $\mathbf{Q}$ & $\mathbf{R}$ \\
\hline fucicola & 0 & 0 & 0 & 0 & 0 & 0 & 0 & $\mathbf{0}$ & 1 & 1 & 0 & 0 & 1 & 0 & 0 & 1 & 1 & 0 \\
\hline berringar & 0 & 0 & 0 & 0 & 0 & 0 & 0 & 0 & 1 & 1 & 0 & 0 & 0 & 1 & 0 & 1 & 1 & 0 \\
\hline cyclodactyla & 0 & 0 & 0 & 0 & 0 & 0 & 0 & 0 & 1 & 1 & 1 & 0 & 1 & 0 & 0 & 1 & 0 & 1 \\
\hline hybophora & 0 & 0 & 0 & 0 & 0 & 0 & 0 & 1 & 1 & 0 & 1 & 0 & 1 & 1 & 0 & 1 & 1 & 0 \\
\hline merringannee & 1 & 1 & 0 & 1 & 0 & 0 & 0 & 1 & 1 & 1 & 0 & 0 & 0 & 0 & 1 & 0 & 1 & 0 \\
\hline mokari & 1 & 1 & 1 & 1 & 0 & 0 & 1 & 1 & 0 & 0 & 1 & 1 & 0 & 0 & 0 & 1 & 1 & 1 . \\
\hline numbadi & 1 & 1 & 1 & 1 & 0 & 0 & 1 & 1 & 0 & 0 & 1 & 1 & 0 & 0 & 1 & 1 & 1 & 0 \\
\hline amikai & 1 & 1 & 1 & 1 & 0 & 0 & 1 & 0 & 0 & 0 & 0 & 1 & 0 & 0 & 1 & 1 & 1 & 0 \\
\hline castellana & 1 & 1 & 1 & 1 & 1 & 1 & 1 & 0 & 0 & 0 & 1 & 1 & 0 & 0 & 1 & 1 & 1 & 0 \\
\hline curvata & 1 & 1 & 1 & 1 & 0 & 1 & 1 & 0 & 0 & 1 & 1 & 1 & 1 & 1 & 0 & 1 & 1 & 0 \\
\hline garciai & 1 & 1 & 0 & 1 & 1 & 1 & 1 & 1 & 1 & 0 & 1 & 1 & 1 & 0 & 0 & 0 & 0 & 1 \\
\hline
\end{tabular}

Diagnosis. - Cuticle heavily villose. Urosomite 2 lacking dorsolateral spines. Antenna 1 not geniculate, accessory flagellum 3-articulate. Mandibular palp, articles 1-2 smooth, article 3 not falciform with only 2 unequal E-setae. Male gnathopod 2, merus without distal tooth, palm short, separated from posterior margin by a tooth. Pereiopods 3-4 propodus poorly spinose, coxae of P4 not lobate. Pereiopods 5 to 7, base weakly toothed posteriorly. Uropod 3, peduncle almost twice as long as outer ramus, inner ramus as long as article 1 of outer ramus. Telson without spines.

Etymology. - This species is dedicated to our colleague and friend Dr. A.M. García-Carrascosa, who directed the CHAFARINAS'91 benthic survey.

\section{Discussion}

\section{Morphology and affinities}

As the discovery of new species progresses, the identity of the genus Gammarella becomes better understood, and character intergradation, suggested previously by other authors (Barnard, 1974; McKinney \& Barnard, 1977; Karaman \& Barnard, 1979), is more evident. Nevertheless, differences between the two extremes are so large that Vonk (1988) proposed to retain the genus Nuuanu, including the smaller species.

In an attempt to group all known species of Gammarella, a cluster analysis was performed using 18 morphological characters (see Table I). Each character was defined as 0 for absence and 1 for presence. Numerical taxonomic methods were utilized to enhance the objectivity of the results, helping us to elucidate which are the morphologically related species and which the intermediate species. A dissimilarity matrix was generated using the Manhattan distance index and the UPGMA cluster method (Sneath \& Sokal, 1973; Norusis, 1992). The phenogram (Fig. 5) shows two major groups, A and B, in accordance with the two genera of Vonk's hypothesis. However, within each group we can see one intermediate species with dissimilarity lower than $50 \%$, labeled as A2 and B2. These species, Gammarella merringannee from cluster $\mathrm{A}$ and $G$. garciai from cluster $B$, share morphological characteristics with species from B and A clusters, respectively.

Gammarella merringannee was already identified by Barnard (1974) as an intermediate species, and an evolutionary sequence from $G$. berringar through $G$. merringannee to $G$. mokari was proposed. Gammarella numbadi and $G$. amikai were considered very "advanced" species (with many apomorphic characters). If $G$. merringannee ap- 


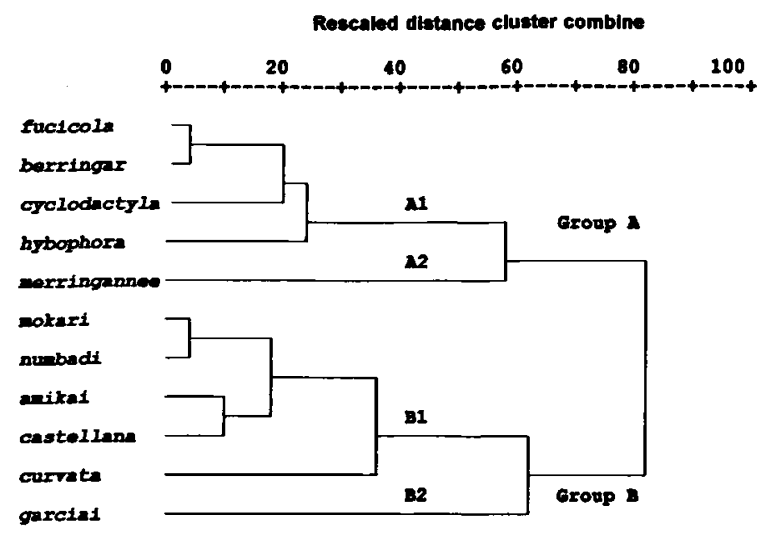

Fig. 5. Phenogram showing morphological similarity of species of Gammarella.

proaches the species from cluster $A$ to species of cluster B, G. garciai does it from cluster B to A. However, it should be kept in mind that the relationships shown in the phenogram reflect only the morphological resemblance of the species. So, inference of phyletic relationships should be made with great caution.

Gammarella garciai is generally similar to the species of cluster B but does not appear to be closely related to any particular species of this cluster. $G$. garciai differs from these species by Al not geniculate, cuticle heavily villose, no tooth on merus of Gn2, and base of P5-7 not castellated. On the other hand, this species shows characters in common with the species of cluster A (G. fucicola, $G$. berringar, G. merringannee, G. cyclodactyla, and $G$. hybophora), but differs in its size, in having reduced eyes, propodus of pereiopods $3-4$ poorly spinose, accessory flagellum with 3 articles, article 3 of mandible palp not falcate, telson deeply cleft, and distinct palm of $\mathrm{Gn} 2$ (male). These characteristics explain the situation of $G$. garciai in the phenogram and confirm the idea proposed in the above paragraph, allowing us to consider $G$. garciai as an intermediate species between cluster $\mathbf{B}$ and $\mathbf{A}$.

In agreement with Barnard \& Barnard (1983), the presence of intermediate species with evident intergradation of characters justifies the existence of a single, unique genus, making doubtful the validity of any generic division.
Key to all known species of Gammarella (cf. Table II)

1. Base of $P 7$, posterior margin castellated .........

- Base of P7, posterior margin serrate ........... 7

2. Length over $8 \mathrm{~mm}$; eyes well developed; urosomite 1 with large reverted dorsal tooth ... G. berringar (Barnard, 1974)

- Length less than $6 \mathrm{~mm}$; eyes weakly developed; urosomite 1 without dorsal tooth $\ldots \ldots \ldots \ldots \ldots \ldots \ldots \ldots \ldots \ldots$

3. Coxa 3 shortened; metasome segments 1-2 untoothed ... .................... G. mokari (Barnard, 1974)

- Coxa 3 as long as coxa 4; metasome segments 1-2 each bearing a single middorsal tooth ..............4

4. Cephalic slit gaping; articles 1-3 of antenna 2 processiferous ................ G. numbadi (Barnard, 1974)

- Cephalic slit not gaping; articles 1-3 of antenna 2 not processiferous ........................... 5

5. Lateral cephalic lobes acute; urosomite 1 with a simple mediodorsal tooth ..........G. castellana (Griffiths, 1977)

- Lateral cephalic lobes quadratiform; urosomite 1 without mediodorsal tooth $\ldots \ldots \ldots \ldots \ldots \ldots \ldots \ldots \ldots \ldots 6$

6. Antenna 1 geniculate; palm of $\mathrm{Gn} 2$ male distinct from posterior margin; U3 inner ramus $<1 / 2$ outer ramus ... ...................... amikai (Barnard, 1970)

- Antenna 1 not geniculate; palm of Gn2 male occupying all the posterior margin; U3 inner ramus $>1 / 2$ outer ramus ................ G. merringannee (Barnard, 1974)

7. Large size, longer than $9 \mathrm{~mm}$; eyes well developed; mandibular palp falciform, article 3 with D-E setae; urosomite 1 carinate $\ldots \ldots \ldots \ldots \ldots \ldots \ldots \ldots \ldots \ldots \ldots . \ldots . \ldots . \ldots$

- Small size, less than $3 \mathrm{~mm}$; eyes little developed; mandibular palp not falciform, article 3 with only E-setae; urosomite 1

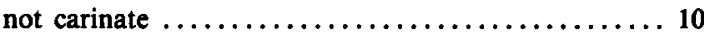

8. Epimeral plate 1 with a large anteroventral curved tooth (hook) .......... G. hybophora Lowry \& Fenwick, 1983

- Epimeral plate 1 with small or without anteroventral tooth 9

9. Telson fully cleft, lacking spines and setae; palm of $\mathrm{Gn} 2$ male with four protuberances and defined from posterior margin ............ G. cyclodactyla (Hirayama, 1978)

- Telson cleft almost to base, with spines and setae; palm of Gn2 male not separated from posterior margin ......... ..................... G. fucicola (Leach, 1814)

10. Antenna 1 geniculate between articles 1-2; epimeral plate 1 with a large anteroventral curved tooth (hook); telson with two spines ................ G. curvata (Vonk, 1988)

- Antenna 1 not geniculate; telson without spines; epimeral plate 1 without anteroventral tooth .... G. garciai n. sp.

\section{Ecology and distribution}

Available ecological data on Gammarella species are difficult to interpret because no data are usually offered with species descriptions. On the other 
Table II. The main differentiating characters of Gammarella species.

fucicola mokari numbadi amikai castellana berringar hybophora merringannee cyclodactyla curvata garciai

Size (mm)

$10-12 \quad 3.2-3.9 \quad 5.8 \quad 3.4-4.5 \quad 4$

8.2-13.3

9.3

$4.4-5.2$

9.3

$2.8 \quad 1.5-2.5$

Eyes well developed

Accessory

flagellum

$n^{\circ}$ arts.

Al geniculate

Md. $\left\{\begin{array}{l}\text { art. } 2 \\ \text { with } \\ \text { setae } \\ \text { art. } 3 \\ \text { with D- } \\ \text { E setae }\end{array}\right.$

$3-5 \quad 3$

6-7 3-6

33

Gn.1

carpus : $2 \times$ propodus

Gn.2 $\left\{\begin{array}{l}\text { Merus } \\ \text { tooth } \\ \text { Carpus } \\ \text { very } \\ \text { short } \\ \text { palm } \\ \text { dis- } \\ \text { tinct }\end{array}\right.$

Propodus

P3-4 very

spinose

Base P7

castellate

Ep1 anteroventral tooth

Urosomite 1 dorsal

margin

carina flush flush frilled a tooth

large

dorsal reverted boss

flush

dorsal

- -

(4-E) (2-E)

boss

Ramus U3

inner :

$1 / 2$ outer

Telson

+ setae + setae + setae + setae + setae

spines spines

+ setae + setae

spines
+ setae

bare

spines setae

Metasomites

1-2 with

dorsal

teeth

(carinate)

(carinate) 


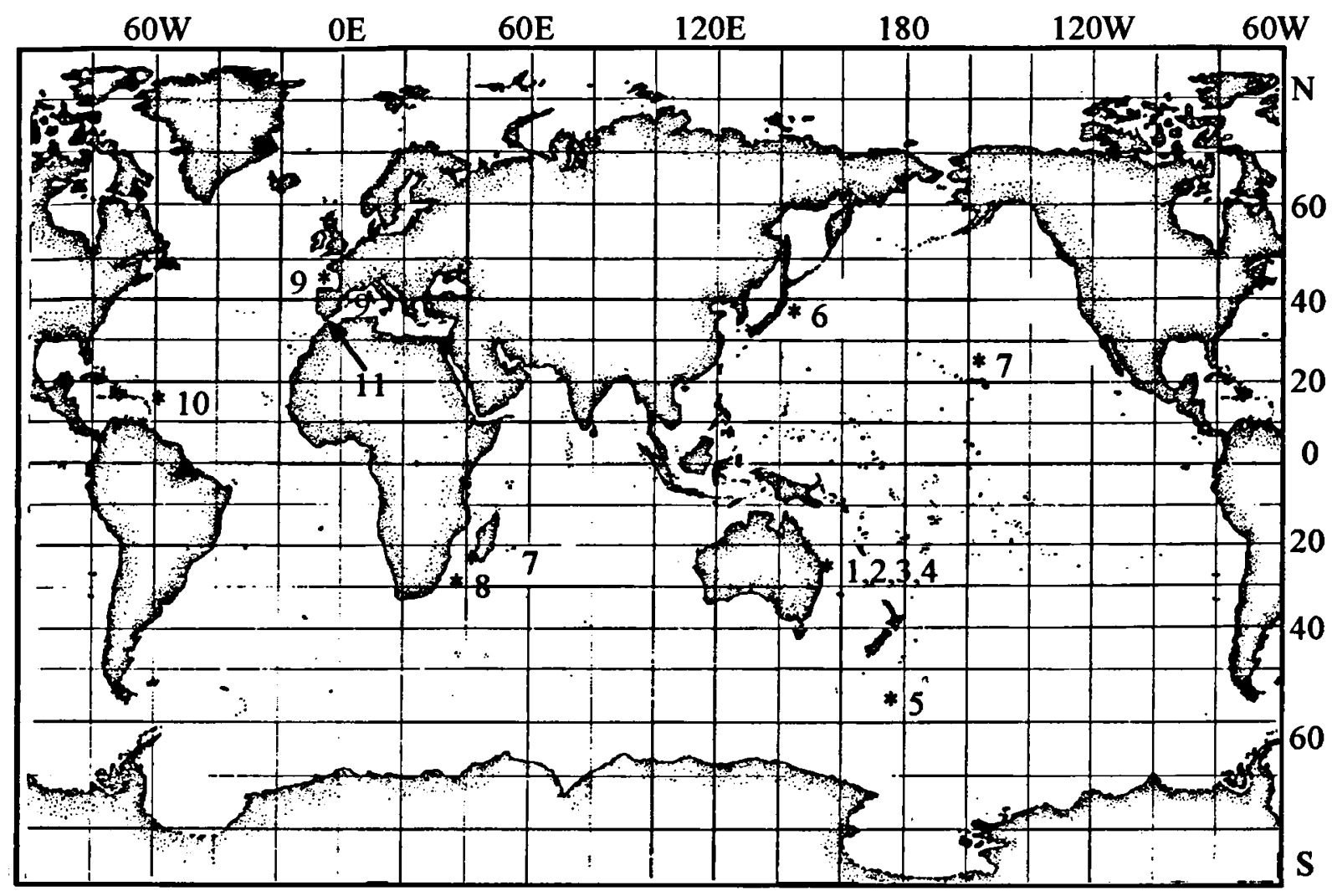

Fig. 6. Map of world distribution of Gammarella species: 1, G. merringannee; 2, G. berringar; 3, G. mokari; 4, G. numbadi (Australia); 5, G. hybophora (Campbell Island); 6, G. cyclodactyla (Japan); 7, G. amikai (Madagascar and Hawaii); 8, G. castellana (South Africa); 9, G. fucicola (Mediterranean Sea including Black Sea, and N.E. Atlantic); 10, G. curvata (Caribbean Sea, Curaçao); 11, G. garciai (Mediterranean Sea, Chafarinas Archipelago).

hand, most descriptions are very recent and species are often known from a single locality (Fig. 6). Gammarella fucicola is the only exception, since it has been frequently recorded from both the Atlantic and Mediterranean. This species is intertidal and sublittoral and found in algae and seagrass. Lowry \& Fenwick (1978) described G. hybophora from intertidal (including shallow pool) to sublittoral (0$50 \mathrm{~m}$ depth) substrata, mainly in deposits of detritus (terrestrial plants), also under boulders (on coarse shelly sand) or with bryozoans. Another species collected from midlittoral (lava) ponds to sublittoral (-18 $\mathrm{m}$ depth, among bryozoans) is G. amikai, identified by Barnard $(1970,1977)$.

Gammarella mokari, G. numbadi, G. berringar, and $G$. merringannee were found by Barnard (1974) in shallow water, without any additional indication about soft or hard substrata. In the same way, poor ecological data are available for $G$. castellana, even when station data of cruises (Louw, 1977) are consulted. This species represents the deepest record for the genus, $-550 \mathrm{~m}$ depth in soft bottom.

Two species are known exclusively from the intertidal zone: Gammarella cyclodactyla in boulder beaches, and $G$. curvata in coarse sand beaches or rockpools. The latter inhabits the macroporous interstitial stygohabitat.

Gammarella garciai $\mathrm{n}$. sp. was recorded from shallow water, $-4.2 \mathrm{~m}$ depth, inhabiting the interstitial system in a sublittoral pool near Posidonia oceanica meadows. The sole species of Gammarella identified from the midlittoral level in the Chafarinas Archipelago was G. fucicola (midlittoral rockpools).

The discovery of the last two species of Gammarella $G$. curvata and $G$. garciai, allows us to take 
into account the hypothesis of Barnard (1974) on the existence of two extremes (evolutionary and ecological) within Gammarella (this hypothesis was referred to the genera Cottesloe and Nuuanu, now synonymized with Gammarella).

In our opinion, the two clusters found using morphological characters may be also considered as representing the two extremes proposed by Barnard (1974). Cluster A groups the larger species, probably nesting ones, with preference for lightless environments (under stones, in boulder beaches, within deposits of plant detritus, within bryozoans, etc.). On the other hand, cluster B groups the smaller species, with eyes poorly developed or absent, showing interstitial preferences. In this way we consider Gammarella amikai, G. curvata, and G. garciai as true stygobionts that have colonized substrata from dimly lighted anchialine waters (lava pond, Barnard, 1977), macroporous interstitia (Vonk, 1988) to a sublittoral interstitial environment.

The genus Gammarella is widely distributed in the world's seas, showing a circumglobal distribution. Species of the genus Gammarella have been mainly identified from Australia, where four are known (Fig. 6). Gammarella fucicola and G. amikai are the only species known from distant geographic areas. The former species has an eastern Atlantic-Mediterranean distribution (including the Black Sea). Gammarella amikai has been reported from Hawaii (Pacific Ocean) and Madagascar (Indian Ocean). Although Gammarella may be considered as a genus of tropical affinity and Tethyan origin (Barnard \& Barnard, 1983), most of the species are known from a single locality, so biogeographical relationships are difficult to establish.

\section{Acknowledgements}

We are grateful to Prof. Sandro Ruffo, Museo Civico di Storia Naturale (Verona, Italy), for critically reading the manuscript and helpful discussions. Grateful thanks are extended to Dr. A. Manuel Garcia Carrascosa, coordinator of the Chafarinas'91 Expedition. Benthos survey in the Chafarinas Islands was possible through a collaboration between ICONA (Institute for Nature Conservation) and the University of València (Spain). The first author was supported in part by a grant (DGICYT.PB92-0121). The second author was supported through F.P.I. and Post-Doc. fellowships from the Spanish Ministry of Science and Education.

\section{References}

Barnard, J.L., 1964. Revision of some families, genera and species of gammaridean Amphipoda. Crustaceana, 7: 49-74.

Barnard, J.L., 1970. Sublittoral Gammaridea (Amphipoda) of the Hawaiian Islands. Smithson. Contr. Zool., 34: 1-286.

Barnard, J.L., 1974. Gammaridean Amphipoda of Australia. Part 2. Smithson. Contr. Zool., 139: 1-148.

Barnard, J.L., 1976. Affinities of Paraniphargus lelouparum Monod, a blind anchialine amphipod (Crustacea) from the Galapagos Islands. Proc. biol. Soc. Wash., 89: 421-432.

Barnard, J.L. 1977. The cavernicolous fauna of Hawaiian lava tubes: 9. Amphipoda (Crustacea) from brackish lava ponds on Hawaii and Maui. Pacific Insects, 179(2-3): 267-299.

Barnard, J.L. \& C.M. Barnard, 1983. Freshwater Amphipoda of the world. I, Evolutionary patterns: i-xviii, 1-358; II, Handbook and bibliography: i-xix, 359-830 (Hayfield Associates, Mt. Vernon, Virginia).

Barnard, J.L. \& C.M. Barnard, 1990. Geographic index to marine Gammaridea (Amphipoda): 1-139 (unpublished; distribution copies available from Smithsonian Institution, Washington, D.C.).

Barnard, J.L. \& G.S. Karaman, 1987. Revisions in classification of gammaridean Amphipoda (Crustacea), part 3. Proc. biol. Soc. Wash., 100(4): 856-875.

Bate, C.S., 1857. A synopsis of the British edriophthalmous Crustacea. Ann. Mag. nat. Hist., (2) 19: 135-152.

Bousfield, E.L., 1973. Shallow water gammaridean Amphipoda of New England: i-xii, 1-312 (Comstock Pub. Associates \& Cornell Univ. Press, Ithaca \& London).

Bousfield, E.L., 1977. A new look at the systematics of gammaroidean amphipods of the world. Crustaceana, Suppl. 4: $282-316$.

Griffiths, C., 1977. The South African Museum's Meiring Naude Cruises, part 6. Amphipoda. Ann. S. Afr. Mus., 74(4): 105-123.

Hirayama, A., 1978. A new gammaridean Amphipoda, Cottesloe cyclodactyla sp. nov., from Amakusa, South Japan. Publs. Amakusa mar. biol. Lab., 4(3): 243-253.

Karaman, G.S. \& J.L. Barnard, 1979. Classificatory revisions in gammaridean Amphipoda (Crustacea), Part 1. Proc. biol. Soc. Wash., 92(1): 106-165.

Leach, W.E., 1814. Crustaceology. In: D. Brewster (ed.), The Edinburgh Encyclopaedia, 7(2): 385-473 (W. Blackwood, Edinburgh).

Louw, E., 1977. The South African Museum's Meiring Naude Cruises. Part I, station data 1975, 1976. Ann. S. Afr. Mus., 72(8): 147-159.

Lowry, J.K. \& G.D. Fenwick, 1983. The shallow-water gammaridean Amphipoda of the subantarctic islands of New 
Zealand and Australia: Melitidae, Hadziidae. J. R. Soc. New Zealand, 13(4): 201-260.

Norusis, M.J., 1992. SPSS for Windows. Professional statistic release 5: i-ix, 1-348 (SPSS Inc., Chicago).

McKinney, L.D. \& J.L. Barnard, 1977. A new marine genus and species of the Nuuanu-group (Crustacea, Amphipoda) from the Yucatan Peninsula. Proc. biol. Soc. Wash., 90(1): 161171.

Sneath, P.H.A. \& R.R. Sokal, 1973. Numerical taxonomy. The principles and practice of numerical classification: $i-x v, 1-$ 573 (W.H. Freeman and Co., San Francisco).
Villora-Moreno, S., 1993. Heterogeneidad del ambiente intersticial y biodiversidad de la meiofauna: El meiobentos de las islas Chafarinas: 1-325 (Tesis Doctoral, Universitat de València).

Vonk, R., 1988. Nuuanu curvata n. sp. and Melita leiotelson n. sp. (Crustacea, Amphipoda) from beach interstitia on Curaçao. Uitg. natuurw. Studiekring Suriname, 123: 185198.

Received: 24 January 1995 